\title{
COMPARISONS BETWEEN BACKS QUESTIONNAIRE AND OTHER EXISTING QUESTIONNAIRES AGAINST STANDARDS SET BY A SOCIAL SECURITY ORGANIZATION BASED IN A DEVELOPING COUNTRY
}

\author{
Jenn Zhueng Tam¹, Zuraida Mohamed ${ }^{1}$, Sharifa Ezat Wan Puteh² and Noor Hassim Ismail ${ }^{2}$ \\ ${ }^{1}$ Negeri Sembilan State Health Department, Ministry of Health, Malaysia \\ ${ }^{2}$ Department of Community Health, National University of Malaysia Medical Centre, Malaysia
}

Corresponding author: Jenn Zhueng Tam

Email: jztam79@gmail.com

\begin{abstract}
In a country that struggles on safety standards and relying heavily on manual labour, Malaysia over the decade had to be very objective in defining work- relatedness among musculoskeletal disorder cases especially chronic low back pain. The BACKS questionnaire was a proposed Back Apparatus; a Collaboration between National University of Malaysia Medical Centre (UKMMC) with Malaysian Social Security Organization (SOCSO) to assist in determining occupational chronic back pain. In the questionnaire, chronic back pain was defined as minimal cumulative back pain for more than 2 weeks in the past year, Pain Visual Analog Score above $2 \mathrm{~cm}$ and Oswestry Disability Index of above 20\%. Based on the SOCSO registry from 2008 to 2010, 428 (56.3\%) workers of 760 workers with back pain agreed and met the requirements of our study. According to the standards of the Medical Board, the BACKS Tool reported a sensitivity of $62.7 \%$, specificity of $94.5 \%$, positive- predictive value (PPV) of $92.9 \%$ and negative- predictive value (NPV) of $69.0 \%$ with moderate agreement as Kappa value was 0.56 . The BACKS Tool served as a complementary assessment along with visits to the workplace that has its advantages when one would to conduct a self-administered assessment of their workplace by safety and health officers, organizations with limited funding.
\end{abstract}

Keyword: low back pain; occupational; validity

\section{INTRODUCTION}

Over the years, many questionnaires had been developed with regards to assessing low back pain. These tools ranged from work- relatedness, diagnosis of low back pain, low back pain with disability, recovery from disability, prognosis after treatment of back illness and identifying predictive values for the types of employees who could return to work. In a similar note, the World Health Organization (WHO) had taken the effort to develop criteria which included both physical and psychosocial assessments to diagnose low back pain. ${ }^{1}$ In terms of disease identification for research purposes, the Nordic Musculoskeletal Questionnaire was a project funded by the Nordic Council of Ministers among the Scandinavian countries had been shown to have high sensitivity ( 0.9 for cervical spondylosis, 1.0 for shoulder capitis, 1.0 for carpal tunnel syndrome and 0.78 for Raynaud's phenomenon) ${ }^{2}$ and commonly used in many researches and occupations (e.g. industrial workers, nurses, veterinarians, and teachers). ${ }^{3,4,5,6,7}$

There were two main sections of the questionnaire; general close ended questions that identifies the affected body region with musculoskeletal disorders for the past 12 months that lasted for 7 days and another section on detailed accounts in terms of accident related incidents at work or at home to related physical assessments to be conducted by health professionals.

In terms of disability assessment, the Roland-Morris Disability (RMDQ) questionnaire and the Oswestry Low Back Pain (OLBPQ) questionnaire are 2 popular questionnaires that are commonly used in researches. Roland-Morris Disability Questionnaire (RMDQ) was developed based from the Sickness Impact Profile (SIP) in $1981^{8}$ while Oswestry Low Back Pain (OLBPQ) is relatively older validated selfassessed instrument designed 40 years ago by United Kingdom researchers for patients with chronic low back pain. ${ }^{9}$ However, work on developing questionnaires in determining workrelated of chronic back pain have been limited for the past 20 years. Debates had been going on with experts rendering medical scientific evidence with socio- politically driven legislation to be mutually exclusive. ${ }^{10}$

The Netherlands medical experts in 2005 expressed concerns in limitations such observational questionnaires due to its lack of sufficient evidence on dose- exposure response relationships between the employee and the relevant work and non- work related factors that normally required that could be shown in cohort studies. Therefore, the panel of 
experts recommended that the criteria proposed would need to be updated in- keeping with the scientific development within a few years. ${ }^{11}$ This was because the hazard exposure obtained from workers using other study design would be flaunted with recall bias. Acknowledging with the experts' concerns, the practicality of the time consumed to conduct longitudinal studies was commonly limited with attrition bias with occupational relationships and association being overly stretched across the board as shown in previous studies. ${ }^{12-16}$ Interestingly, the high attrition was a course of concern with large individuals who developed chronic back pain during the period of the study. Due to this problem, this study was designed to address the much needed quantitative evidence to define work- relatedness before any effective and strong research could be accepted by the medical fraternity.

Nevertheless, one should not seize to address such challenges and walk away when billions of dollars are at stake annually in the United States alone. ${ }^{17} \mathrm{It}$ is therefore the purpose of this study to validate a newly developed BACKS questionnaire; a proposed Back Apparatus: Collaboration between the National University of Malaysia Medical Centre (UKMMC) with the Malaysian Social Security Organization (SOCSO) for the purpose in determining occupational chronic low back pain. Parameters and measurements to discriminate occupational chronic back pain that were previously identified and confirmed in an earlier study are subjected to concurrent validity testing with existing standards especially in the local population where the questionnaire could be used in the near future. Besides that, data is used to analyze the exposure variables relationships by confirming them via structural equation modeling (SEM).

Basically, the research would measure the interaction between workplace environment with the workers' pre- morbid conditions or innate characteristics. For the benefit of the wider audience, the innate traits of the individuals referred to ones' physical fitness, medical health status and psychological passive coping skills. Individuals who are physically fit would increase the probability of occupational- related chronic low back pain and the suggestion for spinal degeneration due to aging ${ }^{18-21}$ would be unconvincing in the presence of the above factor. In the absence of medical illness or injuries, the occurrence of chronic back pain would increase the probability of work- relatedness. Chronic back pain that occur among individuals with high passive coping skills would increase the probability of workrelatedness. Workplace which practices high ergonomic standards would decrease the probability of occupational chronic back pain. Similarly, individuals with high physical fitness levels would have reduced possibility of to attain chronic back pain disabilities. On the other hand, medical health status and passive coping skills had low or no significant relationship with the severity of the chronic back pain disabilities. Therefore, the objective of this study would be to provide an external validity between the BACKS questionnaire with criteria in determining work- relatedness of non- specific low back pain (WNBP) ${ }^{22}$, and the Back Related Office Work (BROW) Questionnaire ${ }^{23}$ against the decision from the SOCSO Medical Board.

\section{METHODS}

This cross- sectional study was basically a concurrent validity study on cases submitted to SOCSO for benefits and compensation between 2008 to 2010. The chronic low back pain defintion in our study was adapted from the World Health Organization definiton 1 as chronic history of low back pain for at least 12 weeks, more than $20 \mathrm{~mm}$ score on Pain Visual Analog Scale and more than 20\% score on the Oswestry Disability Questionnaire.

The inclusion criteria for the study were workers aged between 20- 60 years old, workers who had history of chronic low back pain and submitted medical benefits and compensation from SOCSO and workers with a history or recurrent chronic low back pain. Individuals who were pregnant, workers with pyogenic back conditions, workers having cancer or on treatment or workers that attained back injuries mainly due to acute accidents or commuting injuries at work were excluded from the study.

Based from SOCSO registry, as much as 754 (19.5\%) cases of back- related injuries (19.5\%) in 2009.18 The sample size for the validity testing could be calculated by using the formula for diagnostic tool development of Jones et al. ${ }^{24}$ The power $(z)$ was kept at 1.96 and the level of significance (w) was 0.05 . Therefore, the total sample needed for this research is 375 respondents or workers. To cater for $10 \%$ drop outs a total of 413 respondents would be identified.

Once the participants were selected, the respondents would be examined for the outcome of the BACKS Tool that measures work- relatedness among employees with chronic back pain against the Back Related Office Workers (BROW) questionnaire, ${ }^{23}$ Work- relatedness of non- specific low back pain (WNBP) questionnaire ${ }^{22}$ and decisions fron the respective Medical Board during the period stated above with the help of the respective SOCSO officers from branches across Malaysia. Therefore, cluster sampling was used to represent the distribution of back pain cases at the respective SOCSO branches. The BACKS questionnaire was 
equipped with a regression model that determined work- relatedness. A BACKS score above 57.3 or probability above $51.8 \%$, the chronic back pain was categorised as work- related.

The distribution of back related injuries (19.5\%) reported to the Malaysian Social Security Organization (SOCSO) was noted to be 754 cases in 2009. ${ }^{25}$ The sample size for the validity testing was calculated using the formula for diagnostic tool development of Jones et al. ${ }^{24}$ The power ( $\mathrm{z}$ ) is kept at 1.96 and the level of significance $(w)$ is 0.05 . Therefore, the total sample needed for this research was 375 respondents or workers. Therefore, the targetted actual sample size was 413 respondents that was identified and recruited for the study (inclusive of possible $10 \%$ or 38 respondents of dropouts).

$$
\begin{aligned}
& N(\text { Sensitivity) }=\underline{T P+F N} \\
& T P+F N=\underline{z^{2} \times(S N(1-S N))} \\
& \mathrm{W}^{2} \\
& =(1.96)^{2}(0.95(1-0.95)) \\
& (0.05)^{2} \\
& =72.99 \\
& \mathrm{~N} \text { (Sensitivity) }=\underline{72.99} \\
& 0.195 \\
& \text { = } 375 \text { participants } \\
& \mathrm{N} \text { (Specificity) }=\underline{\mathrm{TP}+\mathrm{FN}} \\
& 1-\mathrm{P} \\
& T P+F N=\underline{z^{2} \times(S P(1-S P))} \\
& W^{2} \\
& =(1.96)^{2}(0.95(1-0.95)) \\
& (0.05)^{2} \\
& =72.99 \\
& \mathrm{~N} \text { (Specificity) }=\underline{72.99} \\
& 0.805 \\
& \text { = } 91 \text { participants }
\end{aligned}
$$

\section{RESULTS}

Based on the SOCSO registry from 2008 to 2010, 428 (59.4\%)workers of 720 workers with back pain agreed and met the requirements of our study. There were 25 workers $(3.5 \%)$ who did not wish to participate in this study, 76 workers $(10.6 \%)$ were not contactable, while 191 workers $(26.5 \%)$ were excluded from the study as they did not fulfilled the study criteria or the responds in forms were incomplete or of poor quality.
Table 1 described the distribution of the cases that were identified, successfully contacted and agreed to participate in our study according to the states in Malaysia from 2008 to 2010. Table 2 showed the socio- demographic and anthropometric distribution of the respondents that were involved in this study. The state of Johor reported the largest number of claims related with chronic back pain. The mean age was $39.49+9.98$ years old while majority were Malay ethnicity $(42.3 \%)$, males $(89.5 \%)$, general workers $(17.5 \%)$, overweight $(26.84 \pm 4.50 \mathrm{kgm}-2)$ and from the semi- urban state of Perak, Peninsular Malaysia (22.4\%) whom mainly presented with back strain (70.6\%).

Table 3 showed the sensitivity and specificity of BACKS Tool, Netherlands questionnaire (WNBP) and the BROW questionnaire with the standards of the SOCSO Medical Board. According to the standards of the Medical Board, the BACKS Tool reported a sensitivity of $64.5 \%$, specificity of $94.5 \%$, positivepredictive value (PPV) of $93.0 \%$ and negativepredictive value (NPV) of $70.0 \%$ with moderate agreement as Kappa value was 0.58 . In comparison to other existing questionnaires, BACKS Tool reported the highest level of agreement with the benefits allocation of the Medical Board. Other than a lower sensitivity reporting compared to the BROW questionnaire $(69.7 \%)$, BACKS reported the highest overall, specificity, positive, negative predictive values and positive likelihood ratio among the 3 questionnaires used in this study (Table 4). In the study, BACKS was noted to be the best tool for physicians to adopt the standards set by SOCSO, Malaysia with regards to define and verify an employee that complained of a chronic occupational back pain condition.

\section{DISCUSSION}

The objective of the study was to identify adequate number of respondents to validate the BACKS Tool. As much intention was considered in the replications of the distribution of cases registered to SOCSO annually, there were large numbers of input from respondents that did not meet the criteria or definition of chronic back pain that was adapted from WHO. ${ }^{1}$ That degree of selection bias indivertibly influence the distribution of respondents intended to be collected and misclassification of information bias that may have occurred. ${ }^{26}$ 
Table 1: Total respondents that were identified by States in Malaysia

\begin{tabular}{|c|c|c|c|c|}
\hline No. & State & Absolute Total (\%) & Cluster (\%) & Sample (\%) \\
\hline 1. & Johor & $189(26.3)$ & $111(26.2)$ & 68 (15.9) \\
\hline 2. & Sarawak & $96(13.3)$ & $56(13.2)$ & $52(12.1)$ \\
\hline 3. & Malacca & $91(12.6)$ & $53(12.5)$ & $44(10.3)$ \\
\hline & Perak & $78(10.8)$ & $46(10.8)$ & $96(22.4)$ \\
\hline 5. & Penang & $65(9.0)$ & $38(9.0)$ & $42(9.8)$ \\
\hline 6. & Selangor & 64 (8.9) & $38(9.0)$ & $41(9.6)$ \\
\hline 7. & Kedah & $51(7.1)$ & $30(7.1)$ & $28(6.5)$ \\
\hline 8. & Federal Territories & $22(3.1)$ & $13(3.1)$ & $15(3.5)$ \\
\hline 9. & Pahang & $22(3.1)$ & $13(3.1)$ & $10(2.3)$ \\
\hline 10. & Sabah & $17(2.4)$ & $10(2.4)$ & $14(3.3)$ \\
\hline 11. & Negeri Sembilan & $12(1.7)$ & $7(1.7)$ & $15(3.5)$ \\
\hline 12. & Terengganu & $11(1.5)$ & $7(1.7)$ & $2(0.5)$ \\
\hline 13. & Perlis & $2(0.2)$ & $1(0.2)$ & $1(0.2)$ \\
\hline 14. & Kelantan & $0(0)$ & $0(0)$ & $0(0)$ \\
\hline & Total & $720(100.0)$ & $424(100.0)$ & $428(100.0)$ \\
\hline
\end{tabular}

Table 2: Distribution of respondents

\begin{tabular}{|c|c|c|c|c|c|c|c|}
\hline 1. & $\begin{array}{l}\text { Socio- demography and } \\
\text { medical history }\end{array}$ & No. & $\%$ & 1. & $\begin{array}{l}\text { Socio- demography and } \\
\text { medical history }\end{array}$ & No. & $\%$ \\
\hline & a)Gender & 428 & 100.0 & & & 428 & 100.0 \\
\hline & Male & 383 & 89.5 & & & 75 & 17.5 \\
\hline & Female & 45 & 10.5 & & $\begin{array}{l}\text { d)Occupation } \\
\text { General Worker }\end{array}$ & $\begin{array}{l}68 \\
58\end{array}$ & 15.9 \\
\hline & b)Race & 428 & 100.0 & & Operator & 43 & 10.0 \\
\hline & Malay & 181 & 42.3 & & Technician & 39 & 9.1 \\
\hline & Chinese & 164 & 38.3 & & Driver & 33 & 7.7 \\
\hline & Indian & 68 & 15.9 & & Professional & 33 & 7.7 \\
\hline & Others & 10 & 3.5 & 2. & Mechanic & 27 & 6.3 \\
\hline & & & & & $\begin{array}{l}\text { Supervisor } \\
\text { Storekeener }\end{array}$ & 24 & 5.6 \\
\hline & c) Education & 428 & 100.0 & & Storekeeper & 21 & 4.9 \\
\hline & Primary & 13 & 3.0 & & Administrative Worker & 7 & 1.7 \\
\hline & Secondary & 367 & 85.7 & & Others & & \\
\hline & Tertiary & 48 & 11.2 & & Unemployed & Mean & SD \\
\hline & d)Presenting Diagnosis & 428 & 100.0 & & Anthropometry & $\begin{array}{l}39.49 \\
18.86\end{array}$ & $\begin{array}{l}9.982 \\
9.724\end{array}$ \\
\hline & Back Strain & 302 & 70.6 & & a) Age (years old) & & \\
\hline & Prolapse Intervertebral Disc & 91 & 21.3 & & b) Working period & & \\
\hline & Degenerative Spinal Disease & 17 & 4.0 & & (years) & & \\
\hline & Lumbar Spondylosis & 8 & 1.9 & & CD. Ctandard Dovintion & & \\
\hline & Spondylolisthesis & 6 & 1.4 & & SD: Standard Deviation & & \\
\hline & Spinal Stenosis & 4 & 0.9 & & & & \\
\hline
\end{tabular}

However, as mentioned earlier the objective of this study was to validate a questionnaire in terms of sensitivity and specificity in identifying workrelatedness consistent with our Medical Board decisions and therefore an epidemiological generalization of chronic low back pain in Malaysia is limited.

The BACKS Tool that was developed had two main components; determination of work- relatedness and the level of disability as a form of severity assessment of the chronic back pain known as the Oswestry Disability Index (ODI) or assessment. In the BACKS Tool, the ODI would serve as an objective assessment that would be quantitatively documented for physicians 27 for better management, fitness to work assessments and referral decisions. Fitness to work commonly used inter- changeably with return to work. Hamer et al.28 recommended that individuals should return to work 3 months post medical discharge. Thus, the ODI would be a good instrument to be used to gauge 
and monitor the progress of the injured worker under the rehabilitation period.

Base on the result, it was noted that BACKS questionnaire had relatively lower sensitivity on workers that are above 40 years old. Although BACKS illustrate work- relatedness, experts expressed concerns in the relationship between the duration of hazard exposure at work with age; especially for those above 40 years old. The plausible explanation would be the physiological degenerative changes of the spine with cumulative trauma or repetitive strain disorder that provided a synergistic effect in the development of chronic back pain. In short, multiple confounding factors would begin to appear among workers above 40 years old that weakens the ascertainment of workrelatedness.

Table 3: Tools Against Medical Board

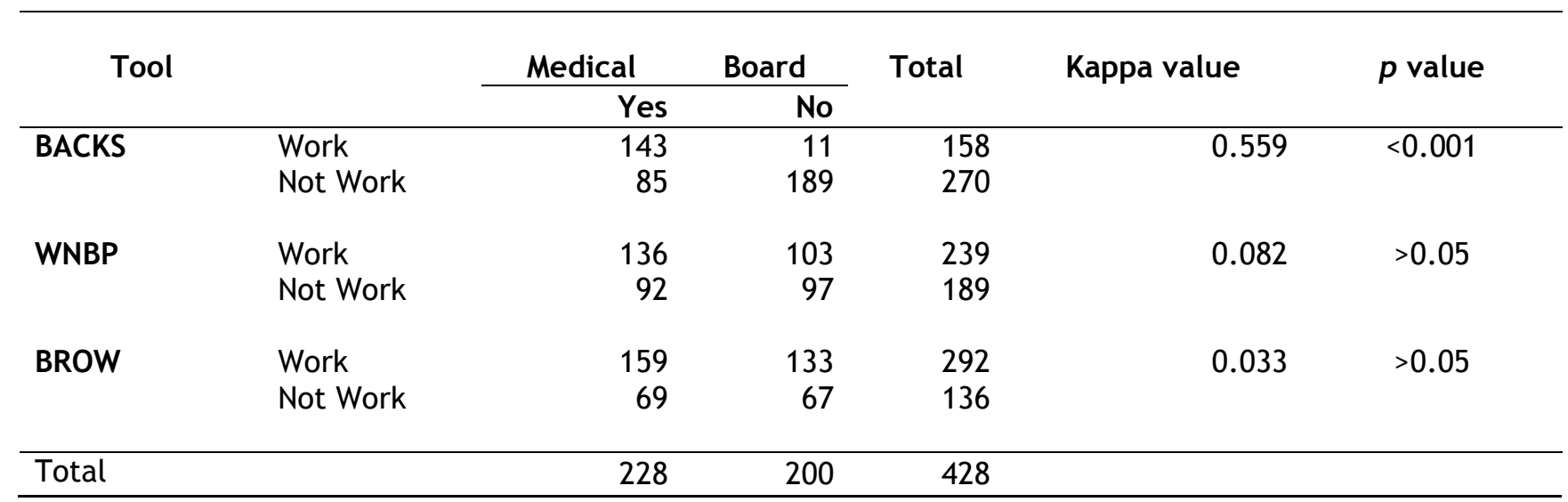

Table 4: Comparisons Between Questionnaires

\begin{tabular}{llccc}
\hline \multirow{2}{*}{ No. } & \multicolumn{2}{c}{ Assesment Parameters } & \multicolumn{3}{c}{ Questionnaires } \\
\cline { 3 - 5 } & & & BACKS & WNBP \\
\hline 1. & Sensitivity & $62.9 \%$ & $59.6 \%$ & $69.7 \%$ \\
2. & Specificity & $94.5 \%$ & $48.5 \%$ & $33.5 \%$ \\
3. & Positive Predictive Value & $90.5 \%$ & $56.9 \%$ & $54.5 \%$ \\
4. & Negative Predictive Value & $70.0 \%$ & $51.3 \%$ & $49.3 \%$ \\
5. & Positive Likelihood Ratio & 11.4 & 1.2 & 1.0 \\
6. & Negative Likelihood Ratio & 0.4 & 0.8 & 0.9 \\
\hline
\end{tabular}

The physical and psychological attributes used in the BACKS Tool were variables identified and consistent with previous studies. 4,6,7,11,12,13,14,15,16,17,22 It would be important to mentioned that majority of the cases that were included in this study were back strain $(70.6 \%)$. However, although psychological and physical demands at work influenced work- relatedness of chronic low back pain, physicians had to be objective in addressing ergonomic- related issues at the workplace with the employers. In fact, psychosocial based ergonomists29 would highlight the associations of psychosocial stress at work contributing to chronic back pain. Such reports would benefit physiotherapist, occupational therapists and counselors to develop interventions or coping mechanisms for workers to return to work and indirectly improve labour productivity. This work clearly showed that back management had to be multi-disciplinary approach and all hygienists and medical personnel had to complement one another with regards to back care.

The current challenge by most physicians was to ascertain whether chronic back pain is associated with multiple medical conditions such as sedentary lifestyles, metabolic disorders and obesity. These physiological conditions would impact on the spine predispose to early onset of degenerative changes to the intervertebral disc. ${ }^{30}$ Thus, the industry would have to invest on lumbar protection and strengthening programs. Therefore, intervention studies or researches on lumbar protection such be greatly encouraged. 
Lastly, BACKS Tool reported the best level of agreement with the decisions of the Malaysian Medical Board of SOCSO. The reported validity levels would be different in a different set of population of workers and diseases. The best explanation was that the BACKS Tool was designed to assist and provide questions on that could be comprehended and reflective of the local lingual differences, workplace and social developments in Malaysia. Therefore, due to differences in cultural and working standards, the Netherlands questionnaire may seem to be less sensitive and not reflective of issues among Malaysian workers. Similarly, the Thailand questionnaire was designed to be given to office workers which explained the relatively low sensitivity and specificity values. The high positive likelihood ratio indicated that the BACKS Tool would have a good reliability in determining occupational chronic low back pain as compared to the other two questionnaires.

\section{CONCLUSION}

It is recommended that the subsequent study should compare the concurrent validity of the BACKS Tool with other existing questionnaires in determining chronic occupational back pain based on current medical standards in a developing heterogenous country such as Malaysia. The ultimate goal of this work would be to develop a standardized rating to define occupational back pain that would costeffective and recognize among physicians to treat the under privileged employees and self-employed entrepreneurs that would provide impact in terms of primary, secondary and tertiary prevention of safety and health on a day to day basis.

BACKS Tool served as a statistical quantitative assessment that had similar objectives of existing qualitative assessment such as workplace survey or an ergonomic health risk assessment that provide importance in preventive health of the workers with chronic back pain. It would provide complementary assessment along with visits to the workplace that has its advantages when one would to conduct a self- administered assessment of their workplace by safety and health officers, organizations with limited funding, developing countries that lack experts such ergonomists. The beneficial of this work would provide a cost- effective adjunct for corporate bodies to assess and re- invent themselves during such challenging times.

\section{ACKNOWLEDGEMENT}

The researchers would like to extend their deepest gratitude to Social Security Organization, Malaysia for the data collection, human resource and financial assistance given. Not forgetting, Mr Chan Kok Fung for the inspiration. Thank you.

\section{REFERENCES}

1. Elrich GE. Low back pain. Bulletin of the World Health Organization 2003; 81:671676.

2. Crawford JO. The Nordic Musculoskeletal Questionnaire. Occup Med (Chic III) 2007; 57(4): 300- 301.

3. Bahr R, Andersen SO, Løken S, et al. Low back pain among endurance athletes with and without specific back loading- a crosssectional survey of cross-country skiers, rowers, orienteerers, and nonathletic controls. Spine 2004; 29(4): 449-454.

4. Hartvigsen J, Lauritzen S, Lings $S$, et al. Intensive education combined with low tech ergonomic intervention does not prevent low back pain in nurses. Occup Environ Med 2005; 62(1):13-17.

5. Ghaffari M, Alipour A, Jensen I, et al. Low Back pain among Iranian industrial workers. Occup Med (Lond) 2006; 56 (7): 455- 460.

6. Mitchell T, O'Sullivan PB, Burnett AF, et al. Low back pain characteristics from undergraduate student to working nurse in Australia: a cross-sectional survey. Int J Nurs Stud 2008; 45(11): 1636-1644.

7. Scuffham AM, Legg SJ, Firth EC, et al. Prevalence and risk factors associated with musculoskeletal discomfort in New Zealand veterinarians. Applied Ergonomics 2010; 41: 444-453.

8. Stratford PW, Binkley J, Solomon P, et al. Defining the minimum level of detectable for the Roland-Morris questionnaire. Phys Ther 1996; Apr; 76(4): 359-65.

9. Niskanen R. The Oswestry low back pain disability questionnaire. A two-year followup of spine surgery patients. Scandinavian Journal of Surgery 2002; 91(2): 208-211.

10. Krawciw D. Spinal Disorders Causation In Melhorn JM. Ackerman WE. Guides to the Evaluation of Disease and Injury Causation. American Medical Association 2008; pg 113133.

11. Kuiper JI, Burdorf A, Frings- Dresen MHW, et. al. Assessing the work- relatedness of nonspecific low- back pain. Scand J Work Environ Health 2005; 31(3): 237- 243. 
12. Miranda H, Viikari- Juntura E, Martikainen $\mathrm{R}$, et al. Individual factors, occupational loading, and physical exercise as predictors of sciatic pain. Spine 2002; Vol. 27: No. 10: pp 1102- 1109.

13. Elders LAM, Heinrich J, Burdorf A. Risk factors for sickness absence because of low back pain among scaffolders- A 3- year follow- up study- Spine 2003; Vol. 28: No. 12: pp 1340- 1346.

14. Elders LAM, Burdorf A. Prevalence, incidence, and recurrence of low back pain in scaffolders during a 3- year follow- up study. Spine 2004; Vol. 29: No. 6: pp E101E106.

15. Turner JA, Franklin G, Fulton- Kehoe D, et al. ISSLS Prize Winner: Early predictors of chronic work disability- A prospective, population- based study of workers with back injuries. Spine 2008; Vol. 33: No. 25: pp 2809- 2818.

16. Kaaria S, Leino- Arjas $P$, Rahkonen $O$, et al. Risk factors of sciatic pain- A prospective study among middle- aged employeesEuropean Journal of Pain 2011; 15: 584590.

17. Guzman J, Esmail R, Karjalainen K, et al. Multidisciplinary rehabilitation for chronic low back pain: systemic review. $\mathrm{Br}$ Med J (Clin Res Ed) 2001; 322: 1511-1516.

18. Campbell C,. Muncer SJ. The cause of low back pain: a network analysis. Soc Sci Med 2005; 60(2): 409- 419.

19. van De Vijver FJR. Bias and substantive analyses. In Harkness JA. van De Vijver FJR, Mohler PPH. Cross- cultural survey methods 2003; John Wiley \& Sons Inc: Canada.

20. Legal Research Board. Employees' Social Security Act 1969 (Act 4), Regulations \& Rules (Revised 2009); International Law Book Services 2009: Direct Art Company: Kuala Lumpur.

21. Hamberg- van Reenen $H H$, Ariens GAM, Blatter BM, et al. Is an imbalance between physical capacity and exposure to workrelated physical factors associated with low- back, neck or shoulder pain? Scand J Work Environ Health 2006; 32 (3): 190- 197.

22. Kuiper JI, Burdoft A, Frings- Dresen MHW, et al. Criteria for determining the work- relatedness of non- specific low- back pain. Coronel Institute of Occupational Health 2004; Amsterdam.

23. Janwantanakul $P$, Pensri $P$, Moolkay $P$, et al. Development of a risk score for low back pain in office workers-a cross-sectional study. BMC Musculoskeletal Disorder 2011; 12: 23.

24. Jones S, Carley S. Harrison M. An introduction to power and sample size estimation. Emergency Medicine Journal. EMJ 2003; 20(5): 453.

25. Aziz Mohammed MA. Trends of industrial and commuting accidents. Social Security Organization 2010.

26. Rothman KJ, Greenland S, Lash TL. Modern Epidemiology (3rd Edition) 2008; Lippincott Williams \& Wilkins, Philadelphia.

27. Yates M., Shastri-Hurst, N. The Oswestry Disability Index. Occupational Medicine. 2017. Volume 67, Issue 3, pg 241-242. [cited 1 December 2018]

28. Gandhi R., Wong S, Mahomed, N. Predicting return to work following treatment of chronic pain disorder. Occupational Medicine 2013. Volume 63, Issue 4, 1 June 2013, pg 253-259.

29. Stratil R, Swincer M. Work- related back pain study: measuring biopsychosocial risk factors. WorkCover Corporation of South Australia 2012. available at https: / / www.google.com/search?rlz=1C1 AOHY_enCH718CH718\&ei=YpOIXJzwH5Dcr QH856LAAw\&q=Stratil+R\%2C+Swincer+M. Work-

+related+back+pain+study\%3A+measuring+ biopsychosocial+risk+factors.++\&oq=Strati $\mathrm{l}+\mathrm{R} \% 2 \mathrm{C}+$ Swincer $+\mathrm{M}$. Work-

+related+back+pain+study\%3A+measuring+ biopsychosocial+risk+factors.++\&gs_l=psyab.3...23922.26115..27572...0.0..0.154.2 $98.0 \mathrm{j} 2 \ldots . . .0 \ldots 1 \mathrm{j} 2 . . \mathrm{gws}$ wiz.OH5u3XrRwww [cited 1 December 2018]

30. Citko A, Gorski S, Marcinowicz L, Gorska A. Sedentary Lifestyle and Nonspecific Low Back Pain in Medical Personnel in NorthEast Poland. BioMed Research International 2018. available at https: / /doi.org/10.1155/2018/1965807. [cited 1 December 2018] 